\title{
O PROGRAMA NACIONAL DE ALIMENTAÇÃO ESCOLAR (PNAE) COMO POLÍTICA DE INCLUSÃO NA AGRICULTURA FAMILIAR DO NORDESTE DO BRASIL*
}

\author{
Emanoel Márcio Nunes** \\ Adriano Costa de Morais**** \\ Joacir Rufino de Aquino***** \\ Ienilton Alves Gurgel ${ }^{* * * * * * *}$
}

\begin{abstract}
Resumo
O objetivo é analisar o Programa Nacional de Alimentação Escolar (PNAE) como ação de inclusão produtiva, a partir dos seus efeitos na agricultura familiar da região Nordeste do Brasil. Como metodologia, os dados são de base secundária, dos sites Instituto Nacional de Estudos e Pesquisa Educacionais Anísio Teixeira (INEP), do Fundo Nacional de Desenvolvimento da Educação (FNDE) e do Portal da Transparência do Governo Federal, tendo como variáveis o número de alunos das escolas municipais e estaduais, os repasses do PNAE nos municípios, e a compra da agricultura familiar por meio da Lei no 11.947/2009. Como resultados, a pesquisa mostrou que o PNAE tem contribuído para a diversificação da agricultura familiar do Nordeste, para o surgimento de organizações coletivas (cooperativas), e para a construção de mercados locais e regionais. Concluindo, a pesquisa destaca a região Nordeste com significativo potencial, especialmente dos municípios menores; no entanto, necessita de estrutura de produção e mecanismos legais para inserir os produtos da agricultura familiar nos mercados.
\end{abstract}

Palavras-chave: Desenvolvimento rural. Alimentação. Agricultura Familiar. Escolas.

\footnotetext{
* Este trabalho faz parte de um conjunto de pesquisas desenvolvidas no âmbito da agricultura familiar e teve auxílio do MDA/SDT/ CNPq, por meio da Chamada Encomendas COSAE MDA 2013 (APQ).

** Doutor em Desenvolvimento Rural pela Universidade Federal do Rio Grande do Sul (PGDR/UFRGS). Professor da graduação e do Programa de Pós-Graduação em Economia (PPE/UERN) da Faculdade de Ciências Econômicas da Universidade do Estado do Rio Grande do Norte (FACEM/UERN). E-mail: emanoelnunes@uern.br

*** Economista. Mestrando em Planejamento e Dinâmicas Territoriais no Semiárido pela Universidade do Estado do Rio Grande do Norte (PLANDITES/UERN). Email: adrianomorais@yahoo.com.br

***** Economista. Mestre em Economia Rural e Regional (UFCG). Professor Adjunto III do Departamento de Economia da Universidade do Estado do Rio Grande do Norte (UERN), Campus de Assú.E-mail: joaciraquino@yahoo.com.br

***** Economista. Mestre em Planejamento e Dinâmicas Territoriais no Semiárido pela Universidade do Estado do Rio Grande do Norte (PLANDITES/UERN).E-mail: ieniltongurgel@yahoo.com.br
} 


\section{Introdução}

Uma das preocupações mais destacadas nas discussões sobre desenvolvimento, especialmente para o meio rural de países e regiões menos desenvolvidos, é encontrar alternativas viáveis em estratégias que levem a atividades com capacidade de inclusão econômica. Nas últimas décadas, houve esforços significativos por parte dos governos e elaboradores de políticas no sentido de ampliar os investimentos na agricultura familiar por meio de mecanismos de política agrícola capazes de inovar na criação e ampliação da estrutura de produção econômica e de organização coletiva dos agricultores familiares. O Programa Nacional de Alimentação Escolar (PNAE), visto como um dos maiores programas de alimentação e nutrição do país (FNDE, 2009) - regulamentado pela Lei Federal no 11.947, de 16 de junho de 2009 -, pode ser considerado uma inovação ao aliar a oferta de alimentação saudável e de qualidade à demanda dos alunos das esferas municipal, estadual e federal. Convém mencionar, ainda, que o PNAE constitui um arranjo institucional formado pelos Conselhos de Alimentação Escolar (CAEs), pelo FNDE, pelo Tribunal de Contas da União (TCU), pela Secretaria Federal de Controle Interno (SFCI) e pelo Ministério Público. E, por ser um mecanismo de política com foco na demanda, o PNAE vem sendo gerido no sentido de promover o desenvolvimento rural, especialmente pela Lei no 1.947/2009, que determina no mínimo 30\% do repasse do Fundo Nacional do Desenvolvimento da Educação (FNDE) para a compra de alimentos da agricultura familiar.

O PNAE tem, nos últimos anos, se apresentado um dos mais importantes mecanismos de política de inclusão no meio rural, por ter se inserido no conceito de alimentação adequada, buscando a valorização da diversificação da agricultura familiar, da sua estruturação econômica e organização coletiva. E, como mecanismo de política pública, busca afirmar o papel da agricultura familiar e reconhecer que os agricultores familiares têm capacidade coletiva para produzir alimentos de qualidade, bem como condições de participar da comercialização direta dos seus produtos, dispensando, conforme determina o art. $4^{\circ}$ da Lei no $11.947 / 2009$, o processo licitatório por meio de chamadas públicas. Por outro lado, o PNAE, de forma inovadora, promove a concepção de território e estimula a interação entre oferta (produção agrícola) e demanda de produtos da agricultura familiar por meio dos recursos disponíveis para as escolas (consumo), além de trazer os seus limites e dificuldades.

Os programas governamentais que fomentam a inclusão produtiva para pessoas de baixa renda da economia, favorecem não só a participação econômica desses indivíduos, mas também contribuem para redução dos desequilíbrios regionais que vigoram por longas décadas nas diferentes 
regiões do país, especialmente, na região Nordeste do Brasil. Outro fenômeno que o incentivo à agricultura familiar proporciona é a gradativa redução da desigualdade social, uma vez que a maioria desses programas estimulam o processo de organização coletiva e são direcionados para os agricultores familiares na perspectiva da inclusão destes na dinâmica da economia.

Pesquisa realizada por Carvalho e Castro (2008) já mostrava que as compras governamentais revelavam um potencial estratégico de desenvolvimento rural regional, com base nos recursos disponíveis e que poderão mobilizar importantes setores econômicos em escala local e regional, enfatizando a importância dessas compras para o fortalecimento das economias municipais e territoriais.

Justifica-se a relevância deste artigo pela possibilidade de o PNAE transformar a agricultura familiar; afinal, tratará da disponibilidade dos recursos disponíveis para os municípios e o acesso aos recursos pelos agricultores familiares. Ademais, buscou-se identificar quais são os desafios para a implementação do PNAE, considerando a necessidade de aplicação da Lei no 11.947/2009, tendo como foco a compra de produtos da agricultura familiar nos pequenos municípios nordestinos.

Assim, as questões centrais deste estudo são "de que maneira o PNAE tem contribuído para a ampliação das ações de Inclusão Produtiva no âmbito da agricultura familiar da região Nordeste do Brasil, região com ainda forte vocação e significativa dependência da atividade agrícola, e detentora de $50 \%$ dos estabelecimentos de agricultores familiares do país?" e "qual é o comportamento do PNAE no que diz respeito à evolução da quantidade de municípios que atingiram a aquisição de $30 \%$ de recursos por meio da Lei Federal no 11.947 de 16 de junho de 2009?”.

Como hipótese, acredita-se que as ações de Inclusão Produtiva proporcionadas pelo PNAE são relevantes, especialmente para a diversificação da agricultura familiar e para o surgimento de organizações coletivas, especialmente cooperativas. Porém, o desempenho do PNAE na agricultura familiar quanto à aquisição dos $30 \%$ de recursos tem apresentado potencial mais significativo nos municípios menores e ainda tem sido insuficiente para desencadear um processo autônomo de desenvolvimento rural na região Nordeste, comparando especialmente com as regiões Sudeste e Sul do Brasil.

Nesse sentido, o objetivo é analisar o Programa Nacional de Alimentação Escolar (PNAE) como ação de inclusão produtiva na agricultura familiar do Nordeste brasileiro, bem como interpretar e explicar os reflexos da expansão das compras da agricultura familiar a partir da evolução dos municípios que atingiram a aquisição de 30\% de recursos por intermédio da Lei no 11.947/2009. 
A pesquisa tem como limite territorial a região Nordeste do Brasil, com uma população de mais 50 milhões de habitantes, possui $20 \%$ do território brasileiro e onde vivem $29 \%$ da população do país. Na região Nordeste originam-se, aproximadamente, $14 \%$ da produção nacional total (medida pelo $\mathrm{PIB}$ ), $12 \%$ da produção industrial e quase $21 \%$ da produção agrícola. Cabe destacar que na região residem $23,5 \%$ da população urbana do Brasil e 46\% de sua população rural (IBGE, 2010).

Para a realização deste artigo, optou-se por fazer uma pesquisa bibliográfica e documental sobre o tema; e, nessa perspectiva, foram consultados autores como Nunes (2009), Nunes e Schneider (2014), Schneider e Tartaruga (2004), Ribeiro, Cerrati e Broch (2013), entre outros, que tratam da temática e poderiam contribuir para o enriquecimento da pesquisa. Os dados que foram utilizados na pesquisa são de origem secundária, extraídos de órgão governamentais como: Instituto Nacional de Estudos e Pesquisa Educacionais Anísio Teixeira (INEP), do Fundo Nacional de Desenvolvimento da Educação (FNDE), Instituto Brasileiro de Geografia e Estatística (IBGE) e o Portal da Transparência do Governo Federal. A fim de atingir os objetivos propostos, foi realizada uma análise comparativa entre os recursos disponíveis e a produção da agricultura familiar, com o propósito de compreender a relação de oferta e demanda estabelecido pelo PNAE no Nordeste do Brasil.

\section{Políticas Públicas, Agricultura Familiar e Políticas de Desenvolvimento do Nordeste nas Últimas Décadas}

As políticas introduzidas no Nordeste brasileiro nas últimas décadas trouxeram modelos nacionais, sem ao menos considerarem as especificidades da região, uma de suas limitações era a de não priorizar um desenvolvimento para dentro, reproduzindo assim modelos de concentração econômica. Tais modelos estão expostos nos polos de crescimento industriais: petroquímico em Camaçari (Bahia) e mineroalumínio (Maranhão) e têxtil (Ceará); e dos agrícolas: polo agroindustrial de Petrolina (Pernambuco) e Juazeiro (Bahia). Os referidos modelos receberam influência da crença desenvolvimentista do pós-Guerra, por meio de renomados autores internacionais, como François Perroux, Gunnar Myrdal, Albert Hirschman, e outros ligados à Cepal, a exemplo de Celso Furtado e Raul Prebisch (NUNES; SCHNEIDER, 2014).

O crescimento econômico da região Nordeste - de certa forma retardatário e dependente da dinâmica da região Centro-Sul - que durante muitas décadas caracterizou o contexto econômico regional, foi substituído pelo forte dinamismo de numerosas atividades que se desenvolveram nas últimas décadas. Mas a pobreza e as desigualdades continuam como 
características ainda marcantes do Nordeste, quando visto no contexto nacional, um traço antigo que as receitas econômicas das últimas décadas não conseguiram alterar significativamente (ARAÚJO, 1997).

Entre os anos de 1960 e 1990 a região Nordeste apresentou um relevante desempenho em termos de desenvolvimento, iniciado a partir do Grupo de Trabalho para o Desenvolvimento do Nordeste (GTDN) e impulsionado pela ação do Estado por meio dos incentivos fiscais 34/18-Finor e pela isenção do imposto sobre a renda, entre outras políticas de caráter regional. No total, entre 1960 e 1990, o PIB do Nordeste quase sextuplicou, passando de US\$8,6 bilhões para US\$ 50 bilhões (ARAÚJO, 1997).

De fato, as políticas públicas da região Nordeste sempre estiveram voltadas para a concepção de que os problemas se resolveriam com o abastecimento hídrico, o que motivou a criação do Departamento Nacional de Obras Contra as Secas (DNOCS), com o intuito de atender tais demandas. A crise hídrica de 1958 mostrou que as ações feitas pelo DNOCS - construções de açudes, cisternas etc. - não bastavam, deveria haver a modernização dos fatores. A partir de então, foram criados a Superintendência de Desenvolvimento do Nordeste (SUDENE) e o Banco do Nordeste do Brasil (BNB), que passariam a atuar como agentes responsáveis pela modernização da economia regional.

A região Nordeste sempre enfrentou problemas que não eram somente restritos ao abastecimento de água, mas também ao baixo poder aquisitivo e à forte disparidade de renda, o que se traduzia em uma deficiência e insuficiência do investimento privado, além de uma agricultura precária predominantemente de subsistência. Cabe ressaltar que a produção agrícola do Nordeste sempre enfrentou problemas sazonais, o que dificulta e limita o desempenho da maioria dos produtores no meio rural.

No período de 1950 até 2010, a região Nordeste experimentou um ciclo de crescimento econômico e de mudanças na sua estrutura de produção econômica, em que diferentes contextos se definem a partir de modelos predominantes no meio rural, resultados das políticas agrárias e agrícolas nacionais e de desenvolvimento regional. Tais mudanças se devem, de um lado, à manutenção e persistência de velhas instituições que buscam a reprodução do modelo econômico dependente e associado à dinâmica da região CentroSul do Brasil, com atividades modernizadas em grandes empresas e, de outro, ao surgimento de novas instituições, que buscam um desenvolvimento considerando a agregação de valor nas atividades tradicionais por meio da agricultura familiar (NUNES; SCHNEIDER, 2014).

Oliveira (2006) destaca que a agricultura familiar do semiárido tem grande importância tanto econômica como social, por contar com mais de $62 \%$ dos estabelecimentos rurais do Nordeste e responder por $30 \%$ 
do valor bruto de toda a produção agropecuária nordestina. A área que constitui o semiárido produz principalmente alimentos básicos, além de ser a principal geradora de mão de obra por ter em torno de $58 \%$ do pessoal ocupado de toda região Nordeste. Ou seja, nos anos pós-1960, o Nordeste - tradicional região produtora de bens de consumo não duráveis (têxtil e alimentar, principalmente) - transformou-se em uma região industrial mais especializada em bens intermediários, com destaque para a instalação do polo petroquímico de Camaçari, na Bahia, e do complexo minerometalúrgico, no Maranhão. Já sua base agrícola se especializou na oferta de produtos cujo beneficiamento acontece fora da região Nordeste, a exemplo das frutas produzidas com irrigação e enviadas in natura para o mercado internacional (ARAÚJO, 1997).

Considerando a integração da região Nordeste à dinâmica econômica da região Centro-Sul, esta estratégia resultou na dependência do Nordeste em relação às regiões mais desenvolvidas. Assim, segundo Araújo (1997, p. 170):

O planejamento para o Nordeste passava pelo Estado em promover o avanço capitalista, patrocinando a acumulação privada por meio de capitais exógenos. Assim, buscava-se, em 1975, a partir do II Plano Nacional de Desenvolvimento, o II PND, construir, no Nordeste, uma infraestrutura em polos de crescimento, utilizandose da perspectiva de Hirschman (1961), Perroux (1964) e Myrdal (1972), os quais desempenhariam o papel de espaços econômicos para atividades modernas e de alto potencial em substituição às atividades tradicionais.

Os investimentos aplicados no Nordeste apresentavam algumas características comuns: intensivos de capital, produção de bens intermediários destinados à exportação para indústrias do centro-sul ou exterior, sendo pouco absorvedores de mão de obra. As políticas implantadas para o desenvolvimento do Nordeste no período acima estudado fizeram com que a economia nordestina crescesse a um ritmo maior do que a economia do Brasil, porém tais políticas não foram capazes de reduzir de forma significativa a pobreza e a desigualdade, sendo estes os problemas mais sérios. Isso porque até os anos 1980 eram políticas concentradoras de renda, tanto do ponto de vista social como espacial. Ao mesmo tempo em que determinada parte do Nordeste desenvolve atividades modernas, no semiárido a crise do algodão contribui para tornar ainda mais difícil e frágil a sobrevivência do imenso contingente populacional dos espaços dominados pelo complexo pecuária/agricultura de sequeiro (ARAÚJO, 2000).

Nessas áreas, os agricultores familiares, rendeiros, meeiros e parceiros produzem; mas, por ser uma agricultura pobre, sem agregação de valor, não 
conseguem acumular. Descapitalizados ao final de cada ciclo produtivo, são incapazes de dispor de meios para enfrentar períodos de seca. Portanto, percebe-se que não houve mudanças significativas e as que aconteceram, em geral, tiveram impactos negativos, como o desaparecimento da cultura do algodão e a quebra do binômio algodão-pecuária. Outro fator a destacar foi a elevada concentração de terras, pois muitos venderam os seus sítios e mudaram para as cidades estimulados pelo processo de urbanização do país. De acordo com o Araújo (2000), de positivo destaca-se somente a extensão da ação previdenciária, cobrindo parte da população idosa e assegurando uma renda mínima, mas permanente, às famílias do semiárido.

$\mathrm{Na}$ década de 1990, iniciou uma redefinição do papel do estado e um redirecionamento dos projetos para o Nordeste buscando uma nova lógica, agora a de uma integração territorial - teorizada por autores como Friedmann e Weaver (1981 apud NUNES, 2009) e Putnam (1993 apud NUNES, 2009) - que se sustentava nos seguintes elementos-chave: a inovação como vetor para o desenvolvimento endógeno, a hierarquia horizontal, a diversidade, o aprendizado social, a conservação dos recursos e da cultura local, e a desconcentração do espaço. A defesa desta ênfase inicia a discussão de uma perspectiva de desenvolvimento que emerge "de baixo" ou bottom-up. Ou seja, incapaz de acompanhar as rápidas mudanças em curso, o Estado passou a sofrer sucessivas alterações nas suas funções e incumbências, que lhe haviam sido atribuídas com maior intensidade a partir de meados do século XX.

Conforme explicam Schneider e Tartaruga (2004), o Estado modificou-se desde as suas estruturas até o caráter de suas ações, deixando de ser o indutor do desenvolvimento econômico e passando a ser o seu regulador, alterando o seu caráter centralizador para uma forma mais suscetível e permeável à participação das diversas instâncias e organizações da sociedade civil. Por isso:

O enfoque territorial é permeável às noções de governança (interação e regulação entre atores, instituições e Estado) e de concertação social ou coordenação de interesses de atores que transcorrem em um espaço determinado que é o território. Tanto a governança como a participação passam a ser entendidas como de fundamental importância para determinar o novo papel das organizações e instituições locais. (SCHNEIDER; TARTARUGA, 2004, p. 113).

Para Abramovay, Magalhães e Schroder (2010), isso favoreceu o avanço no estudo das regiões rurais em pelo menos quatro dimensões básicas. A primeira dimensão abandonou o horizonte estritamente setorial, que considerava a agricultura como um único setor e os agricultores como os únicos atores do meio rural. A segunda impediu a confusão entre crescimento econômico e processo de desenvolvimento. A terceira 
diz respeito ao estudo empírico dos atores e de suas organizações para compreender as especificidades locais. Por fim, a quarta se referiu ao fato de o território enfatizar a maneira de como uma sociedade utiliza os recursos que dispõe em sua organização produtiva.

Essa transição democrática orientou algumas ações do Estado no sentido de superar a pobreza, principalmente no Nordeste, como compromisso político e ético prioritário. E, a partir de 2003, o enfrentamento da pobreza via a introdução de uma nova forma de gestão das políticas públicas por meio da inclusão da dimensão territorial, participativa e descentralizada, onde os processos e os espaços de gestão de um território previam a convivência democrática de atores do Estado e da sociedade civil.

As políticas públicas de desenvolvimento territorial foram estruturadas para a solução de antigos e novos problemas brasileiros, como a pobreza, a desigualdade regional e o desenvolvimento sustentável (DELGADO; BONNAL; LEITE, 2007). Essa interação visava à criação de políticas com foco na demanda para gerar desenvolvimento endógeno nos territórios e uma das mais estimuladas foi a da segurança alimentar, como forma de garantir alimentos de maior qualidade aos alunos e também gerar a inclusão econômica dos agricultores familiares de municípios nordestinos.

\section{Programa Nacional de Alimentação Escolar (PNAE): processo histórico e seus instrumentos legais}

Os programas de alimentação escolar no Brasil têm uma história longa, remontando à década de 1940. Desde então, foram implementadas diversas reformas políticas de grande porte até a criação definitiva do Programa Nacional de Alimentação Escolar (PNAE). A fome e a desnutrição foram reconhecidas como problemas críticos de saúde pública no país, e a Comissão Nacional de Alimentação (CNA) foi criada nesse ano e, quase dez anos depois, foi criada a Companhia Nacional de Alimentação Escolar (CNAE), com doações de alimentos enviados pela comunidade internacional (PEIXINHO, 2013).

Entre 1955 e 1970, observou-se o surgimento de um programa nacional de alimentação escolar, de responsabilidade do governo federal e com abrangência nacional. No entanto, durante este período, as intervenções de alimentação escolar implementadas no Brasil ocorreram mediante parcerias com organizações internacionais cujas principais preocupações eram os alimentos e a nutrição - principalmente no que dizia respeito à saúde por meio da alimentação das crianças.

$\mathrm{Na}$ segunda fase, durante a década de 1960, quase todos os alimentos consumidos nas escolas brasileiras que participavam de projetos de alimentação escolar eram, na realidade, fornecidos pela Food for Peace (em 
português, Alimentos para a Paz), um programa da Agência dos Estados Unidos para o Desenvolvimento Internacional (USAID). Como parte da Food for Peace, a USAID financiava a compra de alimentos produzidos nos EUA ou pelo Programa Mundial de Alimentos. Da mesma forma, não foi dada atenção à necessidade de considerar a adequação cultural dos alimentos fornecidos - ou mesmo se eles eram, ou não, aceitos e respeitavam o hábito alimentar das crianças brasileiras. A década de 1970 trouxe uma mudança: grandes empresas nacionais passaram a fornecer os alimentos adquiridos pelo programa de alimentação escolar, substituindo os alimentos importados e doados pelo Food for Peace. Então, alimentos processados, produzidos por grandes empresas alimentícias começaram a chegar às mesas das escolas brasileiras (PEIXINHO, 2013).

O período de 1970 até o final da década de 1980 foi marcado pela ascensão e pelo declínio dos alimentos formulados introduzidos na alimentação escolar. $\mathrm{O}$ fato é que os cardápios eram pobres em qualidade e sabor, e objetivavam apenas desenvolver as indústrias nacionais do ramo, fortemente asseguradas por esse mercado governamental. Nesse período, o processo de aquisição era centralizado. $O$ governo federal costumava definir o mesmo cardápio para todas as regiões do país, sem considerar os hábitos culturais, as práticas alimentares e as preferências das diferentes regiões brasileiras, acarretando uma série de problemas, destacando-se dificuldades logísticas de armazenamento e de transporte dos alimentos dentro do Brasil, acabando por ocasionar a perda e o desperdício de parte considerável dos alimentos adquiridos.

Em 1979, foi criado o Programa Nacional de Alimentação Escolar (PNAE), mas somente com a promulgação da Constituição de 1988 foi assegurado o direito à alimentação escolar a todos os alunos do ensino fundamental, como programa suplementar à política educacional. Em 1993, iniciou-se o processo de descentralização dos recursos financeiros destinados ao PNAE para os estados e municípios com o intuito de aperfeiçoar o desempenho, introduzir mudanças na sistemática de compras, implantar a produção alternativa de alimentos, utilizar produtos básicos in natura e semielaborados da localidade, o que permitiu melhorar a aceitabilidade das refeições e diversificar os cardápios.

A promulgação da Constituição Federal de 1988 representou um marco, ou um divisor de águas na alimentação escolar no Brasil. No seu art. 208, a Constituição consagra o direito universal à alimentação escolar para os alunos que frequentam o ensino básico em escolas públicas. $\mathrm{O}$ mesmo artigo também imputa ao Estado a responsabilidade de garantir o cumprimento desse direito (BRASIL, 1988). Assim, o Estado - esferas federal, estadual e municipal - deve garantir que todos os alunos da educação básica no Brasil tenham acesso à alimentação escolar. A Constituição foi caracterizada por 
um grau elevado de descentralização na prestação de serviços sociais, de modo geral, e da educação em particular.

Em julho de 1994, a Lei no 8.913/94 determinou a descentralização dos recursos financeiros dedicados à alimentação escolar, e as secretarias de educação dos municípios, estados e do Distrito Federal passaram a ser responsáveis por aplicar os recursos públicos federais destinados à alimentação escolar - ou seja, eram as entidades de execução do PNAE. Em 1998, o Fundo Nacional de Desenvolvimento da Educação (FNDE) passou a ser o órgão do Governo Federal responsável pela gestão do Programa. Todavia, foi a sanção da Lei no 11.947/2009 que ampliou o Programa Nacional de Alimentação Escolar (PNAE), o qual dispõe sobre a utilização de, no mínimo, 30\% dos recursos repassados pelo Fundo Nacional de Desenvolvimento da Educação (FNDE) para alimentação escolar, na compra de produtos da agricultura familiar e do empreendedor familiar rural ou de suas organizações. Essa determinação priorizou os assentamentos de reforma agrária, as comunidades tradicionais indígenas e as comunidades quilombolas, de acordo com o seu art. 14 (BRASIL, 2003).

Com o seu novo quadro jurídico, uma vez que abrange tanto a Lei no $11.947 / 2009$ quanto as resoluções 38/2009 e 26/2013 do FNDE, o PNAE se tornou um mecanismo importante para fortalecer a demanda estruturada pelos alimentos produzidos por agricultores familiares locais. Foi a partir da Lei no 8.913/94 que descentralizou o PNAE sem necessidades de convênios ou acordos, que se passou a transferência direta dos recursos federais para estados e municípios - para que executassem os referidos programas com foco na alimentação mais saudável - e que também promoveu a dinamização da economia local dos territórios. Em 2009, com a promulgação da Lei no 11.947/2009, o PNAE foi ampliado: tornou-se obrigatório o uso de, no mínimo, 30\% dos recursos para a compra de produtos da agricultura familiar e do empreendedor rural (BRASIL, 2003).

De acordo com Nunes e Schneider (2014), o art. 2º, inciso V, da Lei $\mathrm{n}^{\circ} 11.947 / 2009$ prevê essa política como importante instrumento para a promoção do desenvolvimento rural, a qual se dará por meio da compra de produtos de agricultores familiares, estabelecendo uma integração com o Programa de Aquisição de Alimentos (PAA). Essa referência contém uma importante distinção: a de reconhecer a importância da unidade produtiva familiar como sistema de produção capaz de fornecer uma variedade de alimentos saudáveis e de qualidade para a alimentação escolar brasileira. Ainda de acordo com Nunes e Schneider (2014), a partir de 2010, a União iniciou o repasse aos estados e municípios de $\mathrm{R} \$ 0,30$ (trinta centavos) por dia para cada aluno em pré-escola, ensino fundamental, ensino médio e educação de jovens e adultos. As creches e as escolas indígenas e quilombolas 
passaram a receber $R \$ 0,60$ (sessenta centavos). Por fim, as escolas que oferecem ensino integral por meio do Programa Mais Educação terão $\mathrm{R} \$$ 0,90 (noventa centavos) por dia.

Desse modo, mudanças significativas têm sido observadas na operacionalização do Programa, que se refletem na melhoria da qualidade dos serviços. Alterações na sistemática de compras, implantação de produção alternativa e diversificada de alimentos e utilização de maior volume de alimentos in natura foram os procedimentos incorporados ao PNAE, especialmente nas duas últimas décadas.

Em seu trabalho, Ribeiro, Ceratti e Broch (2013) destacam que o PNAE tem sido um instrumento capaz de legitimar a sustentabilidade nas suas diferentes dimensões, pois busca valorizar a localização e a regionalização da alimentação escolar; constitui-se em expressivo mercado consumidor de diferentes demandas reprimidas de bens e serviços da economia urbana (gerando renda e oportunidades de inclusão) e rural (ao adquirir produtos da agricultura familiar, mantendo o produtor e sua família no campo); permitindo a inclusão tanto de beneficiários como fornecedores, e respeitando culturas, tradições e comportamentos alimentares tão diferenciados.

Percebe-se que, até então, todas as compras de alimentos estavam submetidas à obrigação de seguir os preceitos legais de isonomia e concorrência, e abre-se um precedente histórico para o fornecedor caracterizado como "agricultor familiar", ou seja, dispensa-se o processo licitatório, como disposto no seu art. 14. Nessa perspectiva, o PNAE passa a se apresentar como um mecanismo a ser utilizado como uma política de caráter estruturante e inclusiva, ao abrir a possibilidade de adquirir os produtos alimentícios de agricultores familiares locais, levando renda para agricultores e comerciantes onde pouco existia. Mas, com relação a sua efetivação em nível local, poucas iniciativas tinham sido observadas até a obrigatoriedade por meio do marco legal (TRICHES; SCHNEIDER, 2010).

Com base nisso, o PNAE passou a se configurar uma importante política pública para a construção de uma densidade econômica no meio rural e no interior do Brasil, pois seu foco na demanda e sua complexidade e heterogeneidade, ao mesmo tempo em que subsidia a geração de renda, possibilita a ampliação da oferta de alimentos de qualidade, contribui para o regaste de valores da agricultura familiar e permite o desenvolvimento rural nos níveis local e regional.

\section{O PNAE e a agricultura familiar no Nordeste do Brasil}

O histórico de intervenções do Estado brasileiro, com vistas a aumentar a produção agrícola, sempre foi de priorizar empresas agrícolas, 
produtores e cooperativas de grande porte, com abundância de recursos de capital e de infraestrutura, que tinha como objetivo alcançar níveis de economias de escala e reduzir os preços dos alimentos. No entanto, a consequência foi uma série de problemas sociais e desastres ambientais, especificamente: os incentivos à produção de commodities agrícolas, ao invés de culturas alimentares, menor diversidade de alimentos, concentração de terra e migração de áreas rurais para áreas urbanas.

Os instrumentos tradicionais usados para apoiar a produção agrícola no Brasil - como o crédito subsidiado, o crédito usado para formação de capital de giro e os preços mínimos garantidos - não eram acessíveis pelos agricultores familiares. A maioria desses instrumentos requeriam certo nível de capital inicial e capacidade de endividamento e níveis mais elevados de organização coletiva que eram viáveis apenas para os produtores de médio e grande porte. Tais instrumentos também tendiam a favorecer os produtores de culturas que são commodities (DELGADO; CONCEIÇÃO; OLIVEIRA, 2005).

Foi por meio das discussões territoriais que a Lei no 11.947/2009 foi implantada e que comenta sobre o Programa nacional de Alimentação Escolar (PNAE), importante para o desenvolvimento rural, sobretudo para a agricultura familiar. $\mathrm{O}$ art. $2^{\circ}$, inciso $\mathrm{V}$, dessa lei prevê essa política como importante instrumento para a promoção do desenvolvimento rural, a qual se dará por meio da compra de produtos de agricultores familiares, em uma integração com o Programa Aquisição de Alimentos (PAA). Esta referência contém uma importante distinção: a de "[...] reconhecer a unidade produtiva familiar como sistema diversificado de produção capaz de fornecer alimentos saudáveis e de qualidade" (NUNES; SCHNEIDER, 2014, p. 118).

A aplicação dos 30\% dos recursos do PNAE à aquisição de alimentos da agricultura familiar, um dos pontos de análise do PNAE no Nordeste, depende da atuação dos gestores locais do PNAE (estados e municípios), a quem cumpre identificar agricultores familiares aptos a fornecer gêneros alimentícios, assim como da capacidade de produção do segmento da agricultura familiar. O Gráfico 1 mostra o potencial da demanda do PNAE por região do país, destacando a região Nordeste como a segunda de maior capacidade de consumo de alimentos, estando atrás apenas da região Sudeste. 


\section{Gráfico 1 - PNAE: distribuição dos recursos por região - 2011 (\%)}

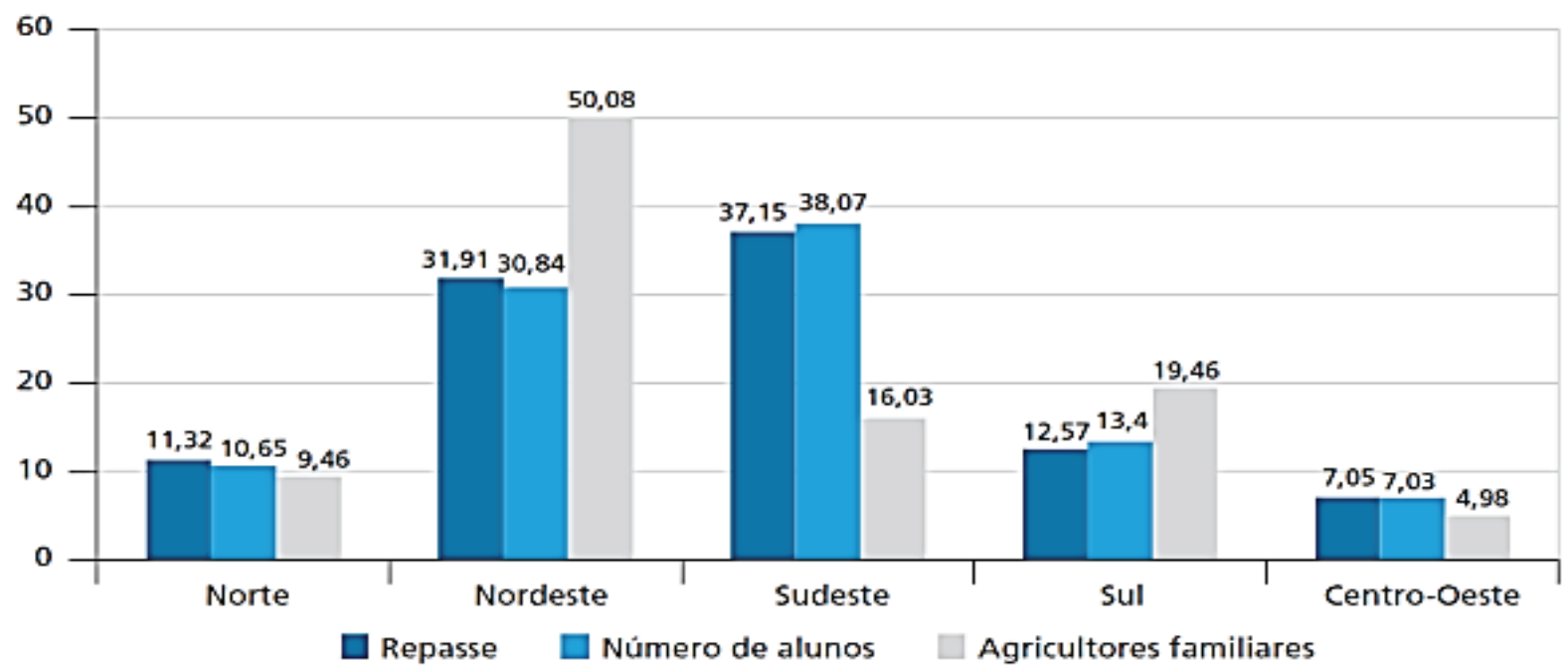

Fonte: Adaptado de PNAE e Nunes e Schneider (2014).

Percebe-se, portanto, que a região Nordeste é a que tem o maior percentual de agricultores familiares do Brasil (50,08\% dos estabelecimentos familiares) e recebe cerca de $30 \%$ do total dos recursos, um pouco menos que a região Sudeste que recebe $37 \%$ dos recursos do PNAE. Vale ressaltar que a maioria dos agricultores familiares do Nordeste ainda não se modernizou e possui uma insuficiente e deficiente estrutura de produção, além de uma frágil e recente organização coletiva, o que dificulta o acesso às políticas públicas e sua ampliação na agricultura familiar, inclusive ao PNAE.

O gráfico apresentado a seguir mostra que a maioria das entidades executoras (escolas estaduais e municipais) que apresentaram seus relatórios de despesas adquire uma parcela de seus alimentos da agricultura familiar, usando recursos do PNAE. Em 2012, aproximadamente 67\% deles adquiriam produtos da agricultura familiar para a alimentação dos alunos de suas respectivas jurisdições. Este valor representa um aumento de quase 20\% em relação ao indicador de 2010 (48\%), revelando um aumento expressivo do número de entidades que compram de agricultores familiares.

O Gráfico 2 mostra o desempenho por região e enfatiza que na região do Sul do Brasil, na qual os agricultores familiares possuem uma maior e mais eficiente estrutura de produção, além de uma organização coletiva mais desenvolvida, incluindo níveis de adesão a cooperativas, redes etc. mais altos do que os de outras regiões. Nota-se que as entidades executoras tiveram um desempenho excelente já desde o primeiro ano de vigência da nova legislação. A região Nordeste, embora tenha uma agricultura ainda desestruturada e pouca organização coletiva, ampliou a aquisição de produtos da agricultura familiar. 
Gráfico 2 - Entidades executoras que compram da agricultura familiar pelo PNAE por Região, 2010-2012 (\%)

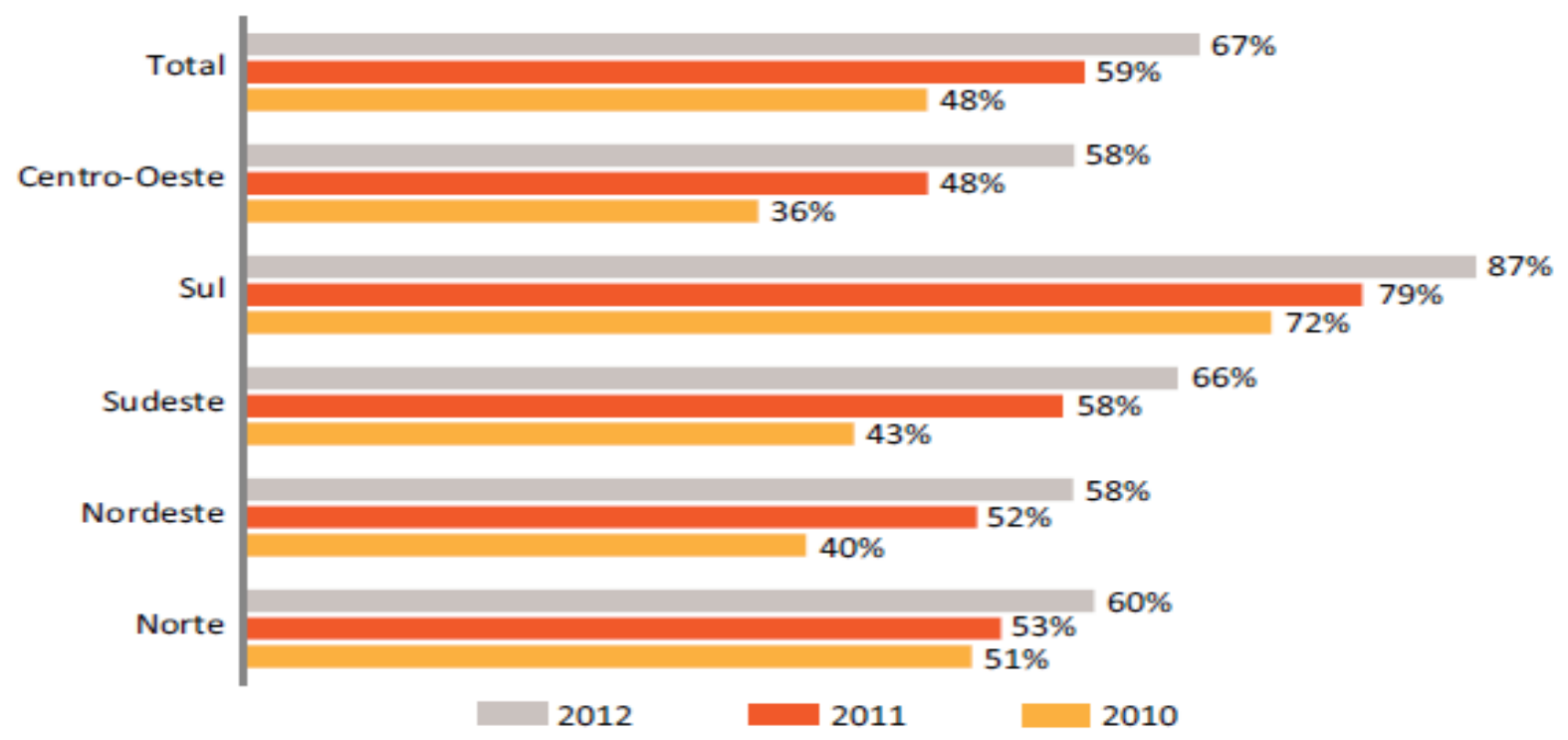

Fonte: FNDE (2014).

Quando se fala em quantidade de recursos que chegaram até os agricultores familiares por meio do PNAE, as Tabelas 1 e 2 mostram que foram destinados para o Programa em 2011, quase 3 bilhões de reais. Contudo, somente $7,85 \%$ dos recursos destinaram-se à aquisição de produtos da agricultura familiar. No Nordeste, essa porcentagem é menor (7,37\%) apesar de a região ter recebido o segundo maior volume de recursos, isso devido a inúmeros fatores, entre eles municípios que não compraram nada da agricultura familiar. De acordo com o FNDE, mais de $40 \%$ dos municípios do país receberam o recurso, mas compraram de outros fornecedores ${ }^{1}$. No Nordeste, a porcentagem chegou a $48,5 \%$ em 2011, o que se deve, provavelmente, à deficiência de estrutura, organização coletiva e de mecanismos legais para inserir os produtos da agricultura familiar no mercado.

$1 \mathrm{O}$ fato de possuir uma estrutura de produção e de organização coletiva ainda deficiente e insuficiente, além da falta de mecanismos legais, a agricultura familiar do Nordeste encontra dificuldades de produzir e ofertar alimentos para a demanda do consumo efetivo do PNAE, o que faz com que grande parte dos municípios da região decidam não comprar ou comprar de outros fornecedores (até mesmo produtos de outros estados), para cumprir com a demanda por alimentos das escolas municipais e estaduais. 
Tabela 1 - Recursos do FNDE para o PNAE por Região em 2011

\begin{tabular}{lccc}
\hline & Recursos transferidos (R\$) & Aquisição AF* (R\$) & \% DA AF* \\
\hline Brasil & $2.990 .297 .175,20$ & $234.670 .508,55$ & 7,85 \\
Nordeste & $928.632 .360,00$ & $68.462 .969,50$ & 7,37 \\
Norte & $319.262 .052,00$ & $23.542 .048,22$ & 7,37 \\
Sul & $397.683 .696,00$ & $48.534 .491,67$ & 12,2 \\
Sudeste & $1.126 .917 .189,20$ & $79.741 .347,59$ & 7,08 \\
Centro Oeste & $217.801 .878,00$ & $14.389 .651,57$ & 6,61 \\
RN & $55.791 .786,00$ & $8.057 .619,63$ & 14,44 \\
\hline
\end{tabular}

*AF - Agricultura Familiar

Fonte: Adaptada de FNDE (2018).

Tabela 2 - Recursos do FNDE para o PNAE por Região em 2014

\begin{tabular}{|c|c|c|c|}
\hline & Recursos transferidos $(\mathrm{R} \$)$ & Aquisição AF* (R\$) & $\% \mathrm{DAAF}^{*}$ \\
\hline Brasil & $3.326 .551 .245,20$ & $711.282 .907,50$ & 21,38 \\
\hline Nordeste & $1.077 .745 .599,40$ & $190.268 .440,18$ & 17,65 \\
\hline Norte & $363.782 .313,60$ & $86.488 .539,14$ & 23,77 \\
\hline Sul & $438.685 .206,80$ & $155.501 .228,78$ & 35,45 \\
\hline Sudeste & $2.649 .360 .765,60$ & $574.832 .258,59$ & 21,7 \\
\hline Centro Oeste & $229.368 .162,80$ & $45.646 .319,36$ & 19,9 \\
\hline $\mathrm{RN}$ & $62.870 .278,80$ & $12.869 .838,18$ & 20,47 \\
\hline
\end{tabular}

*AF - Agricultura Familiar

Fonte: Adaptada de FNDE (2018).

Como se observa na Tabela 2, no ano de 2014 os recursos aumentaram, bem como a parcela destes destinada para a agricultura familiar. Apesar desse aumento, apenas a região Sul conseguiu atingir os 30\% recomendados pela Lei no 11.947/2009. Além disso, percebe-se que, mesmo não atingindo o percentual dos 30\%, a região Nordeste teve um crescente aumento na participação, pois dos 1.633 municípios que recebem o recurso, 1.170 compraram da agricultura familiar mais de 70\%. Esse aumento mostra que, apesar da seca dos últimos anos na região Nordeste, os agricultores familiares criaram cooperativas, produziram e participaram desse mercado institucional que tem se mostrado garantido para a comercialização direta dos seus produtos.

No Gráfico 3, os dados da pesquisa revelam uma evolução do percentual da aquisição de produtos da agricultura familiar na região Nordeste. Destaca-se que, apesar de mais de cinco anos de seca, a ação inclusiva do PNAE conseguiu estimular ou incentivar os agricultores familiares da região. A Lei no 11.947/2009 gerou mudanças na execução do PNAE, devido ao novo desenho descentralizado e com maior 
funcionalidade, cujos maiores efeitos foram na região Nordeste o PNAE, especialmente nos municípios possuidores de menor população.

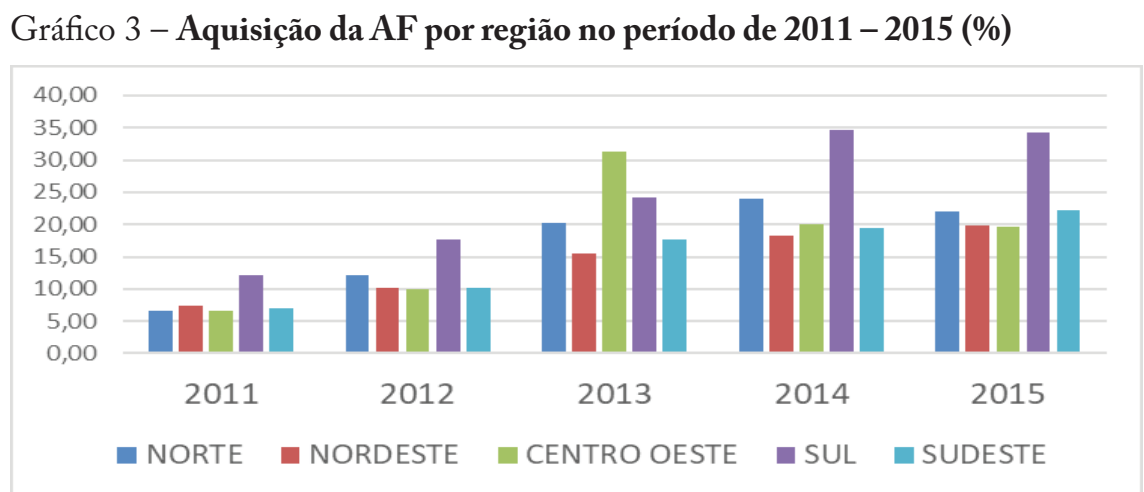

Fonte: Adaptado de FNDE (2018).

Quando se trata do segmento da agricultura familiar, apesar de a região não estar atingindo o mínimo exigido, o PNAE se apresenta como um importante instrumento para garantir o escoamento da produção, e uma abertura significativa da visão dos agricultores familiares para um nicho de mercado cuja dimensão era até então desconhecida. E tem sido na esteira das políticas públicas com foco na demanda, a exemplo do PNAE e do PAA, que na região Nordeste vem surgindo um número cada vez maior de organizações coletivas, especialmente cooperativas, conforme mostra o Gráfico 4.

Com o PNAE os agricultores familiares sentiram a necessidade de criar cooperativas, com o objetivo de ampliar a área de comercialização e agregar valor aos seus produtos, evidenciando o seu papel de braço econômico e intermediário entre o cooperado e o mercado, além do seu caráter não lucrativo. É notado em todas as regiões o aumento das organizações coletivas fornecedoras, o que aconteceu mais intensamente a partir do ano de 2009, coincidindo com a exigibilidade da Lei no 11.947/2009.

A partir de 2009 as cooperativas, mais especificamente, foram utilizadas para operacionalizar as políticas com foco na demanda, pois seriam elas a base sob a qual seria construído e desenvolvido um modelo econômico e social no âmbito da agricultura familiar, capaz de ser eficaz na alocação individual dos agricultores familiares no que diz respeito aos resultados alcançados coletivamente. $\mathrm{E}$ um dos reflexos trazidos pela intensificação da ação das cooperativas com o PNAE foi a crescente valorização da agricultura familiar, visto que elas passaram a comercializar produtos mais diversificados.

O Quadro 1 apresenta uma variedade de produtos produzidos pela agricultura familiar na região Nordeste e adquiridos por meio do PNAE, expressando tanto a valorização da diversificação quanto do caráter tradicional dos alimentos regionais, muitos desprezados pelos defensores da modernização, por serem considerados residuais e sem importância 
econômica e analítica. Produtos, a exemplo do feijão verde, arroz vermelho, batata doce, jerimum (abóbora), coentro, carnes de pequenos animais (galinhas, caprinos, peixes etc.) foram introduzidos pelas escolas públicas do Nordeste. Essa ação do PNAE afirma a diversidade dos produtos dos agricultores familiares do Nordeste e tende a reforçar, de forma positiva, hábitos alimentares locais e regionais.

Gráfico 4 - Evolução das Organizações Coletivas Fornecedoras do PNAE no Brasil Organizações coletivas fornecedoras do Pnae

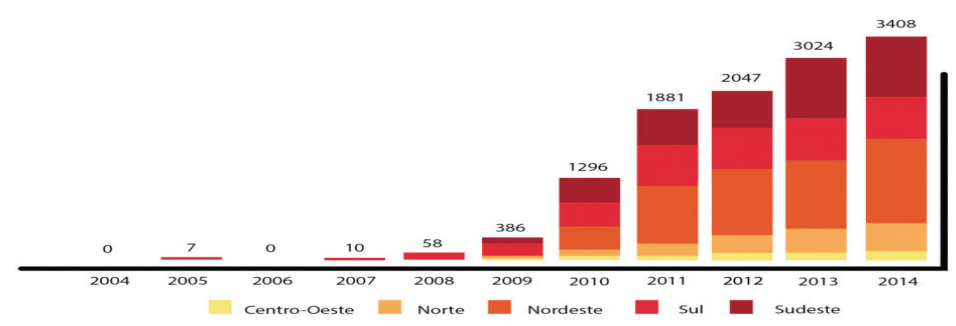

Em 2009, 385 organizaçóes coletivas forneciam para o Pnae. No ano de 2014 , o Pnae já conta com 2961 empreendimentos. um crescimento de $600 \%$

Fonte: Adaptado de FNDE (2017).

Quadro 1 - Principais produtos fornecidos pelos agricultores ao Programa Nacional de Alimentação Escolar (PNAE) no Nordeste, nos anos de 2014 e 2015

\begin{tabular}{|c|c|c|c|}
\hline Hortaliças/Leguminosas & Frutas & Panificados & Carnes/outros \\
\hline abóbora Cabocla & Melancia & Bolo de ovos & Carne de Caprinos de Bovinos \\
\hline Pimentão Verde & Melão & Bolo de leite & Galinha Caipira \\
\hline Coentro & Caju & Biscoito de sequilho & Frango Caipira \\
\hline Alface & Goiaba & Doce de mamão & Mel de Abelha sache \\
\hline Cebola & Graviola & Cocada & Queijo \\
\hline Tomate & Maracujá & Bolo de laranja & Queijo Coalho \\
\hline Abóbora de Leite & Manga & Bolo de milho & Tilápia \\
\hline Feijão Macassar & Mamão & Doce de goiaba & Carne Suína \\
\hline Feijão Verde & Coco verde & Doce de leite & Carne Ovina \\
\hline Cebolinha & Banana & Bolo de macaxeira & Manteiga \\
\hline Arroz Vermelho & Tamarindo & Bolo de cenoura & Bolo de batata \\
\hline Couve & Laranja & Rapadura & \\
\hline Batata Doce & & & \\
\hline Mandioca & & & \\
\hline Pimenta De Cheiro & & & \\
\hline Cenoura & & & \\
\hline Berinjela & & & \\
\hline Repolho & & & \\
\hline
\end{tabular}

Fonte: Adaptado de FNDE (2014). 
Nessa direção, Brasil (2014) destaca pontos importantes a partir do PNAE, tais como: melhoria no consumo a partir de uma alimentação saudável, respeito à cultura e a hábitos alimentares, aquisição de alimentos produzidos localmente etc. Todos esses reflexos são benefícios trazidos pela política por meio do PNAE, considerando o lado dos consumidores; pelo lado dos produtores, o documento destaca que o PNAE se tornou mais uma opção para a estruturação produtiva e de organização coletiva da agricultura familiar do Nordeste. E, em uma interface com políticas de crédito, acompanhamento técnico e o apoio das Universidades, o PNAE pode se traduzir em um mecanismo de construção de uma densidade econômica no interior do Nordeste, que poderá trazer, concomitantemente, a formação de um poderoso tecido social por meio de oportunidades de inclusão.

Nesse sentido, a pesquisa mostrou que juntamente com a evolução das organizações coletivas (cooperativas) e a diversificação de produtos da agricultura familiar adquiridos pelo PNAE, o número de municípios comprando da agricultura familiar cresceu, conforme demonstra o Gráfico 5. Apesar da crise com os consecutivos anos de seca, a agricultura familiar continuou produzindo em pequenos espaços, e, como visto nos dados do gráfico abaixo, a região Nordeste avançou consideravelmente no numero de municípios que compraram algum produto da agricultura familiar com recursos do PNAE.

Gráfico 5 - Evolução dos municípios que atingiram a meta de $30 \%$ de recursos do PNAE da Agricultura Familiar entre 2011 e 2015

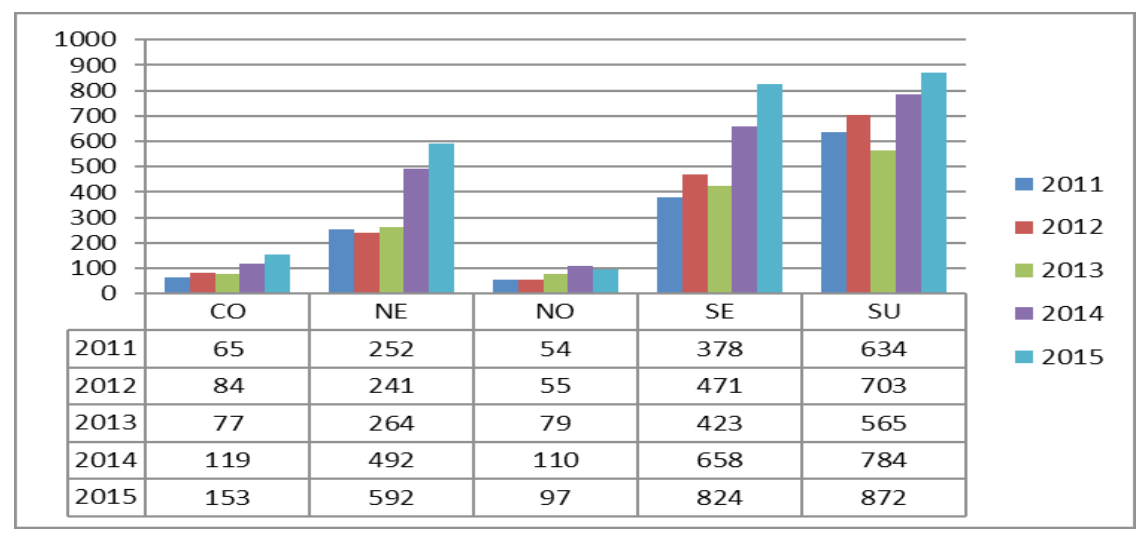

Fonte: Adaptado de FNDE (2017).

Para ter uma ideia, no ano de 2015 um total de 2.538 municípios atenderam ao estabelecido na Lei no $11.947 / 2009$, representando um aumento de $83 \%$ no número de municípios relação a 2011. E a região Nordeste se destacou, pois o numero de municípios dobrou em relação a 2011, saindo de 252 em 2011 para 592 municípios em 2015, o que representou 33\% dos municípios da região. Apesar de a região ter municípios 
que ainda não compraram da agricultura familiar, esta ação demonstra constante crescimento mesmo diante de vários obstáculos e desafios.

No Gráfico 6, as informações mostram que no período de 2011 a 2015, somando os municípios que atingiram a meta dos 30\% e os que compraram alguns produtos da agricultura familiar, também ocorreu um enorme crescimento. A evolução do Nordeste aconteceu quando foram adicionados os municípios que, mesmo não atingindo a meta mínima de aquisição de $30 \%$ do PNAE, compraram algum produto da agricultura familiar neste período, totalizando $80 \%$ dos municípios. Isso fortalece a tese de que a região possui um potencial significativo de expansão.

Gráfico 6 - Evolução do número de municípios que adquiriram com recursos do PNAE da Agricultura Familiar entre 2011 - 2015

\begin{tabular}{|c|c|c|c|c|c|c|}
\hline \multicolumn{7}{|l|}{1600} \\
\hline \multicolumn{7}{|l|}{1400} \\
\hline \multicolumn{7}{|l|}{1200} \\
\hline \multicolumn{7}{|l|}{1000} \\
\hline 800 & \multicolumn{6}{|c|}{600} \\
\hline \multicolumn{7}{|l|}{400} \\
\hline \multicolumn{7}{|r|}{2013} \\
\hline 0 & $\mathrm{CO}$ & $\mathrm{NE}$ & $\mathrm{NO}$ & SE & SU & \multirow{6}{*}{$\begin{array}{r}-2014 \\
-2015\end{array}$} \\
\hline 2011 & 211 & 836 & 196 & 932 & 924 & \\
\hline 2012 & 252 & 944 & 215 & 1055 & 1018 & \\
\hline 2013 & 259 & 996 & 253 & 1062 & 966 & \\
\hline 2014 & 290 & 1319 & 294 & 1273 & 1053 & \\
\hline 2015 & 427 & 1439 & 234 & 1389 & 1129 & \\
\hline
\end{tabular}

Fonte: Adaptado de FNDE (2017).

Mas, diante dos dados apresentados no Nordeste verifica-se que ainda há grandes desafios a enfrentar para que os municípios da região estejam realmente preparados para usufruírem dos recursos do PNAE. Entre eles, destaca-se a dificuldade de os municípios comprarem certos produtos oriundos de produtos derivados de uma das principais atividades do Nordeste: a bovinocultura. Produtos como carnes, leite e derivados (assim como outros de origem animal, por exemplo, ovos, pescados etc.) necessitam de autorização legal, a exemplo dos Serviços de Inspeção Municipal (SIM), Estadual (SIE) e Federal (SIF), para serem comercializados.

Entre os anos de 2013 e 2014 muito desses produtos ainda foram vendidos, mas a sua comercialização começou a ser limitada devido às exigências legais, levando a uma queda na aquisição de produtos da agricultura familiar, principalmente no Nordeste. Dessa forma, para alcançar os níveis de exigência dos órgãos de fiscalização, a agricultura familiar precisa reforçar estratégias no sentido de estruturar sua produção e se organizar mais coletivamente, pontos indispensáveis para se tornar mais competitiva. 
Desafios dos municípios do Nordeste na aquisição de produtos da Agricultura Familiar pelo PNAE

De acordo com o Ministério da Agricultura e Abastecimento (MAPA), a Inspeção de Produtos de Origem Animal é da competência do Departamento de Inspeção de Produtos de Origem Animal (DIPOA), o qual é subordinado à Secretaria de Defesa Agropecuária (DAS). As ações de Inspeção são desenvolvidas em todo o Brasil com respaldo na legislação. As leis são aplicadas e regulamentadas para garantir a qualidade e a segurança dos produtos de origem animal. A oferta desse tipo de alimentos aptos ao consumo, resguardadas as condições higiênico-sanitárias e tecnológicas, é o resultado final da atuação do DIPOA em todo o território brasileiro (MAPA, 2015).

Para atender às exigências do MAPA, foram criados serviços de padronização de carne bovina como, Sistema Brasileiro de Identificação e Certificação de Origem Bovina e Bubalino (SISBOV), SISBI (Sistema Brasileiro de Inspeção de Produtos de Origem Animal (SISBI), Serviço de Inspeção Federal (SIF), Serviço de Inspeção Municipal (SIM), Serviço de Inspeção Estadual (SIE). O Sistema Unificado de Atenção à Sanidade Agropecuária (SUASA), que é um sistema que permite a legalização e a implementação de agroindústrias, através do Decreto no 5.741, de 30 de março de 2006, tem como objetivo harmonizar e padronizar os procedimentos de inspeção e fiscalização de produtos de origem animal em todo país; dessa forma, busca uniformizar os sistemas de inspeção municipal (SIM) e estadual (SIE) com as normas e os procedimentos do SIF (OKAMOTO; AKIYOSHI, 2010).

Os serviços de inspeção e padronização SIM, SIE e SIF são os que regulamentam e padronizam o produto, para que este possa ser comercializado dentro de municípios, estados, território nacional e até mesmo possa ser exportado. A certificação garante ao produto a qualidade especificada na rotulagem, evitando ações oportunistas por parte de produtores ou empresas. "A certificação de produtos, processos, serviços e sistemas de gestão pessoal é realizada por serviços terceirizados tendo como principais objetivos: garantir o nível de qualidade dos produtos e informar ao consumidor que o produto certificado possui os atributos procurados" (BRIDI, 2006).

Os benefícios da certificação atingem tanto o consumidor quanto o fornecedor. Para o consumidor os principais benefícios são: informação sobre o produto e sua qualidade, melhoria nos critérios de escolha, garantia da qualidade do produto, facilidade na avaliação com relação ao preço do produto. Para o fornecedor a certificação garante a abrangência de novos mercados, a diferenciação dos produtos e a agregação de valor. 
Em atendimento às necessidades de apoio para a agricultura familiar, identificadas a partir de amplo debate com os segmentos sociais representativos dos agricultores familiares e com a participação de um leque de parceiros e colaboradores do setor público e privado foi concebido o Programa de Agroindustrialização da Produção dos Agricultores Familiares em 2003, o qual em sua continuidade o MDA elaborou a sua versão 20112014 - (PREZOTTO, 2011).

$\mathrm{O}$ serviço atinge a maior parte de agricultores familiares, tendo esse um maior impacto dentro do território, o objetivo do serviço é controlar a qualidade dos produtos de origem animal e vegetal, como embutidos cárneos, queijos, ovos, mel, doces, abóbora, alface etc.; monitorar e inspecionar a sanidade do rebanho, o local e a higiene da industrialização; e certificar com selo de garantia todos estes produtos. Ao mesmo tempo, o serviço incentiva os agricultores familiares e suas organizações coletivas a oferecerem alimentos com mais qualidade e segurança (Lei no 7.889/89).

Os alimentos produzidos em pequena escala por agroindústrias familiares instaladas em propriedades rurais, que precisam ter equipamentos e estrutura sanitária, passam por um processo de beneficiamento possam ser vendidos ao consumidor. A criação do SIM vem de encontro à necessidade de assegurar ao consumidor alimentos produzidos dentro de normas higiênico-sanitárias satisfatórias, pois reduz os riscos à saúde da população, tira da clandestinidade os produtores artesanais e incentiva a agregação de valor aos produtos e aumento da renda familiar. $\mathrm{O}$ seu objetivo geral é apoiar a inclusão dos agricultores familiares no processo de produção e comercialização, de modo a agregar valor, gerar renda e oportunidades de trabalho no meio rural, proporcionando consequente melhoria das condições de vida das populações beneficiadas, direta e indiretamente.

A adesão ao serviço é voluntária e depende apenas dos administradores de cada município em participar do sistema de inspeção sanitária, por meio do qual atestarão: a saúde dos animais e a sanidade dos vegetais; a idoneidade dos insumos e dos serviços; a identidade, a qualidade e a segurança higiênico-sanitária e tecnológica dos produtos finais destinados ao consumo. Para a agricultura familiar, esse serviço de inspeção facilita a inserção no mercado formal, possibilitando a plena comercialização dos seus produtos, bem como o trâmite para a aprovação e o registro de projetos de forma mais rápida e menos onerosa, podendo impulsionar a implantação de novos empreendimentos. Por sua vez, para os consumidores, tem-se o fortalecimento do foco no controle da qualidade higiênico-sanitária, aumentando a segurança dos alimentos ofertados e comercializados. A descentralização do serviço fortalece a economia dos municípios, abrindo espaço para a integração entre eles, e incentiva o desenvolvimento local e dos territórios. Isso poderá promover a implantação de novas unidades 
agroindustriais e, em consequência, a circulação de maior volume de dinheiro no comércio local, aumentando, também, a arrecadação de tributos nos municípios.

O sucesso da implantação dos SIMs é garantido a partir do compromisso assumido pelos gestores municipais, agricultores familiares, proprietários dos estabelecimentos e responsáveis técnicos, que devem estar sensibilizados para os benefícios e as dificuldades relacionadas às mudanças necessárias ao sucesso do serviço de inspeção. Além disso, deve-se capacitar os técnicos envolvidos nas análises de autocontrole para uma melhoria efetiva na ação fiscal por parte do serviço de inspeção municipal. Outro aspecto que bloqueia a legalização da comercialização de agroindústrias são questões burocráticas e financeiras, porque os trâmites para aprovação e registro dos projetos agroindustriais costumam ser lentos e onerosos. Com a descentralização do serviço de inspeção, esse processo poderá ser mais rápido e barato e poderá impulsionar a implantação de novas agroindústrias. E a questão financeira é mais preocupante para municípios que não têm recurso para arcar com todos os custos da implantação do SIM.

Uma das barreiras encontradas pelos agricultores familiares, em especial do Nordeste, é a inclusão no Serviço de Inspeção Municipal (SIM), o que inicia na sua implantação pelos municípios. Prezotto e Nascimento (2013) enumeram cinco fatores para a não existência do SIM na maioria dos municípios brasileiros: dificuldade financeira, falta de implantação de um Sistema Integrado de Inspeção Sanitária, falta de informações e de orientações sobre o tema, não disponibilização de recursos federais para apoiar a constituição do SIM, desinteresse dos gestores municipais.

Enfim, a legalização é indispensável e representa um dos maiores desafios, especialmente para a agricultura familiar da região Nordeste, para pensar e planejar a ampliação do acesso ao PNAE, assim como de outros mercados. Para isso, será preciso criar as condições para a construção de uma estrutura de produção, o uso adequado do crédito e do acompanhamento técnico, e consolidar os arranjos existentes de organizações coletivas, principalmente as cooperativas. Esses são pontos indispensáveis para tornar a agricultura familiar do Nordeste mais capacitada para construir e manter mercados onde o PNAE tem sido importante.

\section{Considerações finais}

O PNAE tem se mostrado um instrumento capaz de legitimar a sustentabilidade nas suas diferentes dimensões, permitindo a inclusão de consumidores que buscam hábitos alimentares mais saudáveis e de fornecedores com o potencial para ofertar gêneros alimentícios que respeitam culturas e tradições alimentares diversificadas. O PNAE tem 
se apresentado, especialmente na região Nordeste, como um mecanismo de política com expressiva importância para a transformação econômica e social a partir da agricultura familiar e das suas organizações coletivas, com a possibilidade de estimular o desenvolvimento local e regional.

A Lei no 11.947/2009 gerou mudanças na execução do PNAE, e o desenho descentralizado vem apresentando uma maior funcionalidade. Apesar da redução observada na proporção comprada dos agricultores familiares, o PNAE demonstra que, além do desenvolvimento gerado e da garantia do escoamento da produção, foi despertada uma maior valorização para a diversificação da agricultura familiar e para a necessidade de organização coletiva, especialmente cooperativas. Além disso, o PNAE tem sido importante para abrir a visão dos produtores para um novo nicho de mercado.

Diante do exposto, evidencia-se a importância da ampliação e da continuidade do PNAE, considerando que este mecanismo de política tem contribuído no sentido de gerar uma economia mais inclusiva no âmbito da agricultura familiar da região Nordeste do Brasil. E, para consolidar o PNAE como mecanismo de inclusão importante para o processo desenvolvimento rural agrícola e da segurança alimentar e nutricional, é necessário o engajamento de administradores do ensino público - por exemplo, secretários estaduais e municipais, prefeitos, diretores -, de professores, agentes educacionais, pais e comunidade escolar, bem como de agricultores familiares e suas organizações coletivas, pois a oferta de alimentos é muitas vezes reduzida pela falta de especialização da propriedade familiar. Na verdade, em muitos casos os agricultores familiares do Nordeste não se encontram capacitados e com estrutura de produção suficiente para enfrentar as exigências (escala, regularidade, preços, hábitos alimentares, etc.) e a vulnerabilidade do mercado. Então, uma melhoria pode ocorrer por meio de um acompanhamento técnico contínuo, de continuar valorizando cada vez mais a diversificação da produção e reforçando os laços e princípios da organização coletiva, o que deixa os agricultores familiares mais fortalecidos.

Em síntese, foi esclarecida não somente a abrangência do programa na região Nordeste como também a importância do PNAE para a agricultura familiar, na formação de hábitos alimentares e na construção da estrutura produtiva e de organização coletiva dos agricultores familiares. É importe destacar, também, que outras ações precisam ser realizadas para que o PNAE alcance maior número de agricultores familiares, a exemplo da legalização dos produtos por meio do Sistema de Inspeção Municipal (SIM) em todos os municípios do Nordeste. Além do mais, é necessário integrar os mercados intermunicipais, aumentando o relacionamento entre municípios, onde a agricultura familiar se torna peça fundamental para 
dinamizar a economia com mais inclusão, maior diversificação, densidade econômica e tecido social no interior.

\section{Referências}

ABRAMOVAY, R.; MAGALHÃES, R.; SCHRODER, M. Representatividade e inovação na governança dos processos participativos: o caso das organizações brasileiras de agricultores familiares. Sociologias, Porto Alegre, n. 24, p. 268-306, maio/ago. 2010.

ARAÚJO, T. B. de. Herança de diferenciação e futuro de fragmentação. São Paulo: Edusp. Cadernos de Estudos Avançados, n. 11, v. 29, p.7-36, 1997.

ARAÚJO, T. B. de. Nordeste, Nordestes: que Nordestes? In: AFFONSO, R.

B. A., SILVA, P. L. B. Desigualdades Regionais e Desenvolvimento. São Paulo: FUNDAP/ Editora da UNESP. (Série Federalismo no Brasil) p. 125-156, 2000.

BRASIL. Constituição (1988). Constituição da República Federativa do Brasil. Brasília, DF: Senado Federal, 1988.

BRASIL. Lei federal $n^{\circ}$ 11.947, de 16 de junho de 2009. Dispõe sobre o atendimento da alimentação escolar e do Programa Dinheiro Direto na Escola aos alunos da educação básica; altera as Leis nos 10.880 , de 9 de junho de 2004,11.273, de 6 de fevereiro de 2006, 11.507, de 20 de julho de 2007; revoga dispositivos da Medida Provisória no 2.178-36, de 24 de agosto de 2001, e a Lei no 8.913, de 12 de julho de 1994; e dá outras providências. Disponível em: http://www.planalto. gov.br/ccivil_03/_Ato2007-2010/2009/Lei/L11947.htm. Acesso em:

BRASIL. Fundo Nacional de desenvolvimento da Educação. Resolução/CDE/ FNDE $n^{\circ}$ 38, de 16 de julho de 2009. Dispõe sobre o atendimento da alimentação escolar aos alunos da educação básica no Programa Nacional de Alimentação Escolar - PNAE. Disponível em: http:// www.fnde.gov.br. Acesso em: 31 mar. 2018.

BRASIL. Fundo Nacional de desenvolvimento da Educação. Dados sobre os programas de Segurança Alimentar e Nutricional por Município. Brasília: PNAE, 2010. Disponível em: http://www4.planalto.gov.br/consea-1/programaspor-municipios-/pnae. Acesso em: 31 mar. 2018.

BRASIL. Fundo Nacional de desenvolvimento da Educação. Resolução/CDE/ FNDE no 26, de 17 de junho de 2013. Dispõe sobre o atendimento da alimentação escolar aos alunos da educação básica no Programa Nacional de Alimentação Escolar - PNAE. Disponível em: http:// www.fnde.gov.br. Acesso em: 31 mar. 2018.

BRASIL. Fundo Nacional de desenvolvimento da Educação. Merenda escolar. Brasília: FNDE, 2014. Disponível em: http:// www.fnde.gov.br. Acesso em: 31 mar. 2018.

BRASIL. Fundo Nacional de desenvolvimento da Educação. Dados Estatísticos Orçamentos e Alunos Beneficiados. Brasília: FNDE, 2018. Disponível em: http://www.fnde.gov.br/programas/alimentacao-escolar. Acesso em: 31 mar. 2018.

BRIDI, A. M. Padronização, Rastreabilidade e Certificação de Animais e seus Produtos. Universidade Estadual de Londrina. Departamento de zootecnia, Londrina. Disponível em: www.uel.br/pessoal/ambridi/Carnesecarcacasarquivos/ Padronizacao. pdf . Acesso em: 27 marços 2016>. 
CARVALHO, D. G. de; CASTRO, V.M. de. O programa nacional de alimentação escolar - PNAE como política pública de desenvolvimento sustentável: políticas públicas e instrumentos de gestão para o desenvolvimento sustentável. In: ENCONTRO DA SOCIEDADE BRASILEIRA DE ECONOMIA ECOLÓGICA, 2008. Anais [...], Cuiabá MT.

DELGADO, G. C.; CONCEIÇÃO,J. C.P. R. da; OLIVEIRA,J.J. DE. Avaliação do Programa de Aquisição de Alimentos (PAA). Texto para Discussão, no 1145. Brasília: IPEA, 2005.

DELGADO, N. G.; BONNAL, P.; LEITE, S. P. Desenvolvimento territorial: articulação de políticas públicas e atores sociais. Rio de Janeiro, 2007.

INSTITUTO BRASILEIRO DE GEOGRAFIA E ESTATISTICA (IBGE). 2010. Disponível em: https//www.ibge.gov.br. Acesso em: 30 jan. 2018.

NUNES, E. M. Reestruturação agrícola, instituições e desenvolvimento rural no Nordeste: dinâmicas regionais e a diversificação da agricultura familiar no polo Açu-Mossoró (RN). 2009. 351 f. Tese (Doutorado em Desenvolvimento Rural) Programa de Pós-Graduação em Desenvolvimento Rural, Universidade Federal do Rio grande do Sul, Porto Alegre, 2009.

NUNES, Emanoel Márcio. ; SCHNEIDER, Sergio. Reestruturação Agrícola, Instituições e Desenvolvimento Rural no Nordeste: A Diversificação da Agricultura Familiar do Polo Açu-Mossoró (RN). Revista Econômica do Nordeste, Fortaleza, v. 44, n. 3, p. 601-626, jul./set. 2014.

OKAMOTO, O.; AKIYOSHI, G. A. Processo Industrial frigorífico de carne bovino - do abate a exportação. 2010. (Apostila do curso de Processo industrial frigorífico de carne bovino).

PEIXINHO, A. M. L. A trajetória do Programa Nacional de Alimentação Escolar no período de 2003-2010: relato do gestor nacional, Ciência e saúde coletiva, v. 18, n. 4, p. 909-916, 2013.

PREZOTTO, L. L. Material Técnico sobre consórcios de municípios com vistas a adesão ao SUASA, Brasília, novembro de 2011.

PREZOTTO, L. L.; NASCIMENTO, M. A. R. Manual de Orientações Sobre Constituição de Serviço de Inspeção Municipal (SIM). Brasília: SIM, 2013.

RIBEIRO, A. L. P.; CERATTI, S.; BROCH, D. T. Programa Nacional de Alimentação Escolar (PNAE) e a participação da agricultura familiar em municípios do Rio Grande do Sul. Revista Gestão e Desenvolvimento em Contexto, Cruz Alta, v. 1, n. 1, p.36-49, 2013.

SCHNEIDER, S.; TARTARUGA, I. G. P. Território e Abordagem territorial: das referências cognitivas aos aportes aplicados à análise dos processos sociais rurais. Raízes, Campina Grande, 23, n. 1-2, p. 99-116, jan./dez. 2004.

TRICHES, R.; SCHNEIDER, S. Alimentação Escolar e Agricultura Familiar: reconectando o consumo a produção. Saúde Sociedade, São Paulo, v. 19, n. 4, p. 933-945, 2010.

Submetido em: 29/07/2018

Aceito em: 20/11/2018 


\title{
THE NATIONAL SCHOOL FEEDING PROGRAM (PNAE) AS A POLICY OF INCLU- SION IN FAMILY FARMING IN NORTHEAST BRAZIL
}

\begin{abstract}
The objective is to analyze the National School Feeding Program (PNAE) as a productive inclusion action, based in the its effects on family farming in the Northeast region, Brazil. As a methodology, the data are secondary, from the National Institute for Educational Studies and Research (INEP), the National Educational Development Fund (FNDE) and the Transparency Portal of the Federal Government, when the major variables are students from municipal and state schools, PNAE transfers in the municipalities, and the purchase of family agriculture through Law $\mathrm{n}^{\circ}$ 11.947/2009. As a result, the research showed that the PNAE has contributed to the diversification of family farming in the Northeast, to the emergence of collective organizations (cooperatives), and to the construction of local and regional markets. In conclusion, the research highlights the Northeastern region with significant potential, especially in smaller municipalities; however, it needs a production structure and legal mechanisms to insert the products of family agriculture in the markets.
\end{abstract}

Keywords: Rural Development. Feeding. Family Farming. Schools.

\section{EL PROGRAMA NACIONAL DE ALIMENTACIÓN ESCOLAR (PNAE) COMO POLÍTI- CA DE INCLUSIÓN EN LA AGRICULTURA FAMILIAR DEL NORDESTE DE BRASIL}

\begin{abstract}
Resumen
El objetivo es analizar el Programa Nacional de Alimentación Escolar (PNAE) como acción de inclusión productiva, a partir de sus efectos en la agricultura familiar de la región Nordeste de Brasil. Como metodología, los datos son de base secundaria, de los sitios Instituto Nacional de Estudios e Investigación Educacional Anísio Teixeira (INEP), del Fondo Nacional de Desarrollo de la Educación (FNDE) y del Portal de la Transparencia del Gobierno Federal, teniendo como variables el número de alumnos de las escuelas municipales y estatales, los traspasos del PNAE en los municipios, y la compra de la agricultura familiar por medio de la Ley no 11.947/2009. Como resultados, la investigación mostró que el PNAE ha contribuido a la diversificación de la agricultura familiar del Nordeste, para el surgimiento de organizaciones colectivas (cooperativas), y para la construcción de mercados locales y regionales. Concluyendo, la investigación destaca la región Nordeste con significativo potencial, especialmente de los municipios menores, sin embargo necesita de estructura de producción y mecanismos legales para insertar los productos de la agricultura familiar en los mercados.
\end{abstract}

Palabras-clave: Desarrollo rural. Alimentación. Agricultura Familiar. Escuelas. 